\title{
DO MESMO E DO DIFERENTE: DAS CORPORAÇÕES DE OFÍCIO ÀS UNIVERSIDADES CORPORATIVAS
}

\author{
MAURÍCIO BECK ${ }^{1}$, KAROLINE DA CUNHA TEIXEIRA ${ }^{2}$
}

\author{
Programa de Pós-Graduação em Letras: Linguagens e Representações \\ Universidade Estadual de Santa Cruz \\ Rod. Jorge Amado, Km 16 - 45662-900 - Ilhéus, BA - Brasil \\ Programa de Pós-Graduação em Ciências da Linguagem \\ Universidade Federal Fluminense \\ R. Alexandre Moura, 8 - 24210-200 - Niterói, RJ - Brasil \\ $\underline{\text { pardalbeck@gmail.com }}, \underline{\text { karoline ct@hotmail.com }}$
}

\begin{abstract}
Resumo. O escopo deste artigo é analisar o discurso das e sobre as universidades corporativas tendo em conta as memórias que ressoam na história, a saber: as das palavras universidade, educação e corporação (do latim, corporatio); as das antigas corporações de oficio; e as das contemporâneas corporações transnacionais. Com Pêcheux (2010 [1969]), compreendemos que os sentidos não têm origem, nem fim, estão sempre em curso e em relação às condições de produção em que circulam. Formação universitária e treinamento (dos corpos dos trabalhadores) são ressignificados na dialética da paráfrase e da polissemia? Para responder a esta questão, entre outras, tomaremos como corpus os canais do youtube Liderança Educadora e Fundação Dom Cabral.
\end{abstract}

Palavras-chave: universidade; corporações; trabalho intelectual; treinamento.

\begin{abstract}
The aim of this paper is to analyze the discourse of and about corporate universities taking into account the memories that resonate with history, namely: those of the words university, education and corporation (from Latin, corporatio); those of the old craft corporations; and those of contemporary transnational corporations. Based on Pêcheux (2010 [1969], p.76), we understand that the senses have no origin, no end, they are always ongoing and in relation to the conditions of production in which they circulate. Are university education and training (of workers' bodies) resignified in the dialectic of paraphrase and polysemy? In order to answer this question, among others, we will take as our corpus the channels of youtube "Liderança educadora" (Leadership Educator) and "Fundação Dom Cabral" (Dom Cabral Foundation).
\end{abstract}

Keywords: university; corporations; intellectual work; training.

\footnotetext{
${ }^{1}$ Professor e pesquisador no Programa de Pós-Graduação em Letras: Linguagens e Representações da Universidade Estadual de Santa Cruz (UESC). Membro do Coletivo Contradit (Coletivo de Trabalho Discurso e Transformação).

${ }^{2}$ Mestranda em Estudos da Linguagem na Universidade Federal Fluminense.
} 


\section{ESTRANHAMENTO}

Iniciamos esta apresentação na oscilação entre uma obviedade afirmada e o estranho familiar que é evocado na designação "universidade corporativa". O atributo, corporativa, traço diferencial na publicidade de dados estabelecimentos de ensino, significa uma universidade em si, enquanto uma corporação no sentido contemporâneo do termo, ou um para si, enquanto formação direcionada à realização de metas corporativas? Universidade especializada, customizada na tarefa de (con)formar o amálgama de alunos e funcionários em suposta convergência de interesses com dada corporação (o avatar jurídico de uma dada empresa). Ora, mas que curiosa vinculação entre a formação do indivíduo (interpelado, individualizado) e o escopo de um coletivo empresarial. Neste ponto, sentimo-nos tentados a retomar o liberalismo clássico. Com a palavra Adam Smith:

Os privilégios exclusivos das corporações, os estatutos de aprendizagem, e todas aquelas leis que, em empregos determinados, restringem a concorrência a um número de indivíduos inferior ao que, noutras circunstâncias, nela entrariam, tendem a produzir idênticos efeitos [...]. Constituem uma espécie de monopólio em sentido lato e podem, muitas vezes, durante gerações, e para vastos grupos profissionais, manter o preço de mercado de certos bens acima do seu preço natural [...]. (SMITH, 1980, p. 169)

Muitas significações se incrustaram nos significantes Corporation ou corporação desde os tempos do liberalismo clássico de Adam Smith. Afinal, corporação hoje, o que quer dizer? Um pouco de história empresarial pode oferecer-nos alguns indícios:

A Peugeout começou como um negócio familiar [...] Hoje a empresa emprega cerca de 200 mil pessoas em todo o mundo, a maioria delas completamente estranha umas às outras. Esses estranhos cooperam de maneira tão eficaz que em 2008 a Peugeout produziu mais de 1,5 milhão de automóveis, gerando uma receita de aproximadamente 55 bilhões de euros. (HARARI, 2016, p. 36-37)

Harari se pergunta pela existência concreta da Peugeout e ele mesmo responde: sua existência é produto da imaginação coletiva, ou melhor, de uma realidade intersubjetiva (esse efeito da linguagem) que faz laço social entre estranhos dando condições para o trabalho em cooperação de larga escala. No discurso do direito, a Peugeout é compreendida como uma ficção jurídica, uma entidade que está submetida às leis dos países em que opera, assim como os demais sujeitos de direito.

A Pegeout pertence a um gênero particular de ficção jurídica chamado "empresas de responsabilidade limitada". [...] Nos Estados Unidos, o termo técnico para uma empresa de responsabilidade limitada é "corporação", o que é irônico, porque o termo deriva de "corpus" [...] exatamente aquilo de que as corporações carecem. Apesar de não ter um corpo real, o sistema jurídico norte-americano trata as corporações como pessoas jurídicas, como se fossem seres animados de carne e osso. Também foi isso o que fez o sistema jurídico francês em 1896, quando Armand Pegeout, que herdara de seus pais uma oficina de fundição de 
metal que fabricava molas, serrotes e bicicletas, decidiu entrar no ramo de automóveis. (HARARI, 2016, p. 38-39)

Desta ficção jurídica derivam os sentidos contemporâneos para corporação. Entidade animada a quem se atribuem direitos e deveres e a quem se antecipa uma unidade de interesses. Esta, entretanto, é uma concepção de corporação diversa daquela que foi alvo da crítica de Adam Smith. Historicamente as corporações de ofício surgiram e se desenvolveram no meio urbano. Os historiadores remetem sua aparição à Roma antiga, mas é, sobretudo, na baixa Idade Média que as corporações ou guildas vão se destacar na organização do trabalho e do comércio das cidades europeias. Segundo Martins (2008, p. 18), "na lei romana, corpora ou collegia eram as associações voluntárias de indivíduos que compartilhavam a mesma profissão ou função na sociedade." Estas desaparecem com as invasões bárbaras e o declínio da vida urbana e só ressurgem no século XII com "diferentes designações nas várias regiões da Europa: mercadantia ou collegia notariorum, na Itália; confréries, na França; guilds, na Inglaterra, Suécia e Holanda; Innungen, Gilden ou Zünfle, na Alemanha; grêmios, na Espanha”.

Em linhas gerais, as corporações de ofício do Medievo podem ser definidas como associações de trabalhadores (artesãos) de um dado ofício - carpintaria, marcenaria, alfaiataria, sapataria etc. Estas associações regulavam, ensinavam e monopolizavam tais atividades nas cidades mais populosas da Europa pré-Revolução Industrial. Estruturadas de modo hierárquico, estabeleciam uma divisão social do trabalho entre mestres (donos das oficinas, experientes nos respectivos ofícios e responsáveis pelo seu ensino), oficiais (com alguma experiência, tinham direito a um salário) e aprendizes (alunos de ofício sem direito à remuneração). A semelhança desta gradação hierárquica com a do meio acadêmico não é gratuita,

assim nasceu também o intelectual da Idade Média, como um dos homens de ofício que se instalam no meio urbano em crescimento, fazendo parte de uma nova divisão do trabalho. E, neste caso, ao surgimento dos intelectuais teria correspondido o surgimento das universidades medievais e, com ela, o surgimento das corporações de ofícios. Ambas nasceram sob a ambiguidade da liberdade e/ou do privilégio. No entanto, a universidade "não tem, como as demais corporações, o monopólio do mercado local. O seu terreno é a Cristandade". (MARTINS, 2008, p. 21)

A ambiguidade em torno do privilégio da liberdade correspondia à lei "em favor daqueles que viajam com o intuito de estudar e os professores de direito são especialmente mencionados com palavras muito honrosas" (OLIVEIRA, 2006, p. 67). Esta lei, promulgada por Frederico I em novembro de 1158, concedia proteção especial aos estudantes estrangeiros que por amor à ciência enfrentavam tantas dificuldades. Entrementes, o mundo urbano do medievo deu ocasião para o surgimento de universidades e corporações de ofício. Ambas originalmente indiferenciadas segundo os modos de regulação jurídico-estatal da época, mas com escopos e práticas divergentes. Voltada às letras da tradição do direito romano, à hermenêutica do texto bíblico e ou filosófico $^{3}$, a universidade medieval tinha como tarefa a formação de juristas e

\footnotetext{
3 “A Universidade de Paris tornou-se o centro da cristandade latina porque foi nela que as questões mais importantes da humanidade estavam sendo debatidas, elaboradas, defendidas e criticadas,
} 
administradores. Sua esfera de atuação difere das práticas manuais e mecânicas das corporações de ofício. Estas últimas se diferenciam também pelo modo de ensino em que a escrita não tem lugar. É via narrativa oral que o mister $^{4}$ - saber secreto de cada ofício é transmitido para os aprendizes. De modo que há uma divisão social do trabalho que demarcará o destino histórico da universidade e das corporações e vai engendrar a repartição moderna entre o trabalho braçal e o trabalho intelectual. Repartição que enfrenta uma crise contemporaneamente, como veremos adiante.

Com a modernidade industrial, as corporações de ofício entram em decadência e são mesmo proibidas em países europeus (no Brasil, o mesmo ocorre via a Constituição Política do Império do Brasil, vulgo Carta de 1824). O discurso liberal, de Adam Smith e outros, pregava a livre concorrência individual, o valor dos talentos naturais, a regulação dos preços e da atividade fabril pela mão invisível do mercado. Com efeito, o mutualismo corporativo não tinha lugar na terra das oportunidades do livre mercado, onde reinam os homens de negócios. O avanço tecnológico revolucionara as relações de trabalho. A partir de então, o trabalho braçal especializado cede lugar ao trabalho operário padronizado, repetitivo e segmentado submetido à maquinaria fabril. Não há mais lugar para artesãos e seus misteres, apenas para o proletário destituído de tudo exceto sua força trabalho bruta (ou não qualificada) para vender ao menor preço. Em suma, grande parte dos aprendizados de ofícios mecânicos perdem sua razão de ser com a primeira Revolução Industrial.

\section{VIRADA DO SÉCULO XXI}

Nas grandes corporações, o trabalhador letrado e diplomado é, entretanto, desqualificado para executar cargos de liderança. Para tais cargos, há uma variedade de cursos profissionalizantes oferecidos pelas empresas, de modo que esse suposto líder ao final de um dado curso, de gestão de pessoas, por exemplo, seja capaz de ser um doutrinador da cultura e valores da empresa, reforçando a hierarquia laboral nas relações de trabalho e colaborando para o crescimento da empresa e, em uma lógica meritocrática, também para o seu crescimento individual. É esse o enredo que circunda o aparecimento das chamadas universidades corporativas.

A criação das universidades corporativas remete à década de 1980, no cenário norteamericano, discutida há pelo menos 40 anos, desde o lançamento da Crotonville, em 1955, pela General Eletric, nos Estados Unidos (MENEZES, 2015). Com o fim da segunda guerra mundial, os EUA dobram o seu Produto Interno Bruto (PIB), saindo da maior crise geral da era do capitalismo financeiro de 1930. Diante desse contexto de crescimento econômico, as empresas americanas buscavam maneiras de ampliar seus negócios, e a universidade corporativa é criada, porque segundo alguns teóricos (como MEISTER,

pois, era nela que se concentravam as principais tendências filosóficas e teológicas do Ocidente do século XIII" (OLIVEIRA, 2006, p. 71).

4 "Não existiam manuais para os aprendizes ou textos escritos deixados por mestres e oficiais, e mesmo os compromissos das corporações não tinham a função de servirem como compêndios para o ofício. Neles, eram descritos somente os deveres dos artesãos do ofício e os compromissos firmados com os demais membros da corporação. Isso preservava o ofício da possibilidade de certas convenções técnicas caírem em mãos estranhas. A tradição oral contribuía, assim, para a preservação dos segredos ou mistérios do ofício" (MARTINS, 2008, p. 82). 
1999; SENGE, 1996 e STUART, 1998 apud OTRANTO, 2014), a universidade acadêmica era/é incapaz de proporcionar a formação exigida pelo mundo do trabalho em constante reestruturação. A universidade corporativa chega então como uma alternativa para padronizar e qualificar funcionários que, mesmo depois de formados, são julgados como despreparados para assumirem cargos de liderança e, por isso, precisam de constante atualização para atender às demandas do mercado. No Brasil, esse processo de criação de universidades corporativas se deu mais tardiamente, em meados da década de 1990, quando as empresas começam a elaborar o conceito de universidade corporativa como uma capacitação mais ampla em comparação aos tradicionais centros de treinamento e desenvolvimento.

Para este artigo, apresentamos, algumas sequências discursivas do vídeo jornalístico intitulado "O que é universidade corporativa?", a fim de analisar o discurso das e sobre as universidades corporativas tendo em conta as memórias que ressoam na história, a saber: as das palavras universidade, educação e corporação (do latim corporis e actio, corpo e ação). E de como a criação dessas ditas universidades resgatam através da memória discursiva um imaginário de unidade e trabalho em conjunto presente, como já mencionado anteriormente, nas corporações de ofício. Em nosso corpus, a universidade corporativa é significada como um lugar voltado ao "desenvolvimento de líderes" [1'27'] e "não aos operários de fábrica" [0'36'] como os centros de treinamento, a universidade corporativa é significada como um caminho possível para se "chegar lá" [2'12"]. Segundo Mariani e Magalhães (2011, p. 45), "na mídia a visibilidade e a valorização do individualismo e das responsabilidades individuais vai aumentando na mesma proporção em que se defende uma coletivização nacional, enquanto repartição de culpas, destas mesmas responsabilidades sociais e individuais". Ao criar o imaginário de que esses supostos líderes são parte da corporação e não meras peças de manutenção e geração de lucros para um grupo reduzido de pessoas, as grandes empresas asseguram sua "excelência operacional" interna, possibilitando a expansão e importação de empresas internacionais e/ou de seus valores para países como o Brasil. Dentre essas empresas, estão Abril, Banco do Brasil, Banco Itaú, BNDES, Carrefour, Caixa Econômica Federal, Correios, Embraer, Fiat, Globo, entre outras (NASCIMENTO JUNIOR, 2006).

Em pesquisas anteriores (DELA-SILVA; TEIXEIRA, 2017), iniciamos nossa reflexão acerca do modo como a designação "universidade corporativa" é significada pela mídia jornalística brasileira. O vídeo jornalístico que nos propomos a analisar foi exibido na TV no canal GloboNews e está disponível no site de compartilhamentos: Youtube; portanto, faz parte dessa grande mídia, cujo funcionamento se dá em cooperação com outros aparelhos Ideológicos do Estado, como uma tentativa de cristalização dos gestos de interpretação sobre os acontecimentos, uma vez que as relações de força também determinam em grande medida as relações de sentido (PÊCHEUX, 2010 [1969], p. 86). É nesse movimento de retomada e direcionamento de sentidos para a designação universidade corporativa que "o discurso jornalístico contribui na constituição do imaginário social e na cristalização da memória do passado bem como na construção da memória do futuro" (MARIANI, 1998, p. 64), uma vez que ao produzir efeitos de sentido sobre a designação universidade corporativa não o faz fora de uma posição discursiva possível em uma FD dominante inscrita em nossa formação social capitalista, cuja sociedade é dividida pela luta de classes, que se materializa no interior do discurso como relações de poder, pois "o fato de que as classes não sejam "indiferentes" à língua se traduz pelo fato de que todo processo discursivo se inscreve numa relação ideológica de 
classes" (PÊCHEUX, 2009, p. 82, itálico do autor). O discurso é sempre atravessado pela ideologia, que naturaliza as práticas da luta de classes, produzindo o efeito de evidência nos gestos de interpretação do mundo via linguagem.

Em nossas análises, buscamos desautomatizar esses efeitos de evidência, voltando-nos ao modo como os sentidos vão sendo tecidos na materialidade discursiva. Observamos que antes da abertura do programa, temos a vinheta ilustrada no Quadro 1 (figura 1).

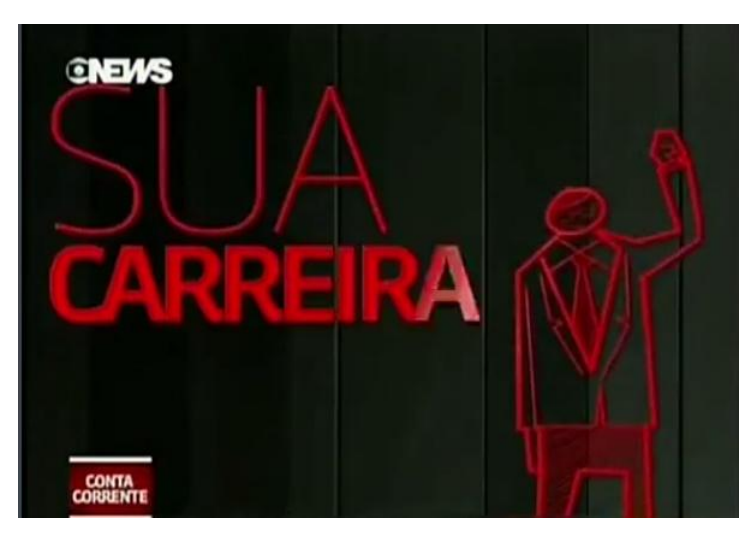

Quadro 1 - Bloco de abertura.

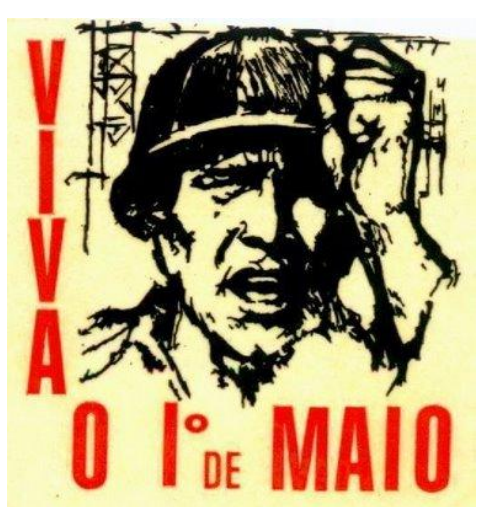

Cartaz $1^{\circ}$ de Maio - Fonte: PSOL Rio das Ostras.

Figura 1 - reprodução das imagens respectivamente: do vídeo jornalístico e google imagens (link da imagem do cartaz https://psolriodasostras.wordpress.com/2011/04/27/1\%C2\%BA-de-maio-relembra-luta-detrabalhadores-e-mostra-resistencia-aos-planos-do-governo-dilmal)

Esse gesto retoma, via memória discursiva, um símbolo de luta da classe trabalhadora, como se marca no cartaz de $1^{\circ}$ de maio (figura 1). Não é por acaso que o discurso do vídeo tem como sustentação um discurso meritocrático e traz um símbolo de luta dos trabalhadores; é na apropriação, ou seja, em sua retomada em outras condições de produção, que um gesto político como esse passa a significar diferentemente no quadro 1 e no cartaz de $1^{\circ}$ de maio. Esse trabalhador que luta por seus direitos e está em conflito com as relações de trabalho é apagado. Esse gesto de levantar a mão com o punho fechado é retomado em um movimento de ressignificação do discurso sobre o trabalho, uma vez que, de acordo com Pêcheux (2010 [1969]),

[...] as diversas formações resultam, elas mesmas, de processos discursivos anteriores (provenientes de outras condições de produção) que deixaram de funcionar, mas, que deram nascimento a "tomadas de posição" implícitas que asseguram a possibilidade do processo discursivo em foco. (PÊCHEUX, 2010 [1969], p. 85)

Desse modo, há um apagamento do político, isto é, da luta de classes; e se sobrepõe o discurso sobre o sucesso profissional, no qual o trabalho é significado como um meio de se chegar "lá", determinando um modo de ser sujeito na atualidade: um sujeito que precisa continuamente se aperfeiçoar, se qualificar para atender às demandas do mercado.

$\mathrm{Na}$ abertura do programa, o âncora do jornal oferece um panorama do tema que será tratado naquele dia: universidade corporativa. Desse modo, podemos entender a designação universidade corporativa como o "referente" sobre o qual se fala. Segundo 
Pêcheux (2010 [1969], p. 82), o referente "pertence igualmente às condições de produção" e "se trata de um objeto imaginário e não da realidade física". Assim, os efeitos de sentido sobre a universidade também se dão através desses mecanismos de projeção, ou seja, a imagem que a posição do jornal faz sobre o que é uma universidade e uma antecipação de que modo isso pode ser falado para que faça sentido para o sujeito telespectador. Como a grande mídia se articula com o poder econômico, esse dizer passa a produzir efeitos de sentido sobre a universidade corporativa que se alinham ao mercado, apagando as disputas de sentidos sobre como deve ser a educação em nosso país e a que demandas ela deve atender. O telejornal é significado no vídeo jornalístico como um lugar que vai descrever, dizer "o que é" a universidade corporativa, produzindo um efeito de neutralidade, que tenta apagar o lugar do jornal como uma posição discursiva dentre outras possíveis. Sob esse foco, selecionamos fragmentos, que tentam responder a pergunta que norteia todo o vídeo, na tentativa de regularizar sentidos através da repetição de argumentos que retomam direta ou indiretamente "universidade corporativa é", como expomos na figura 2 :

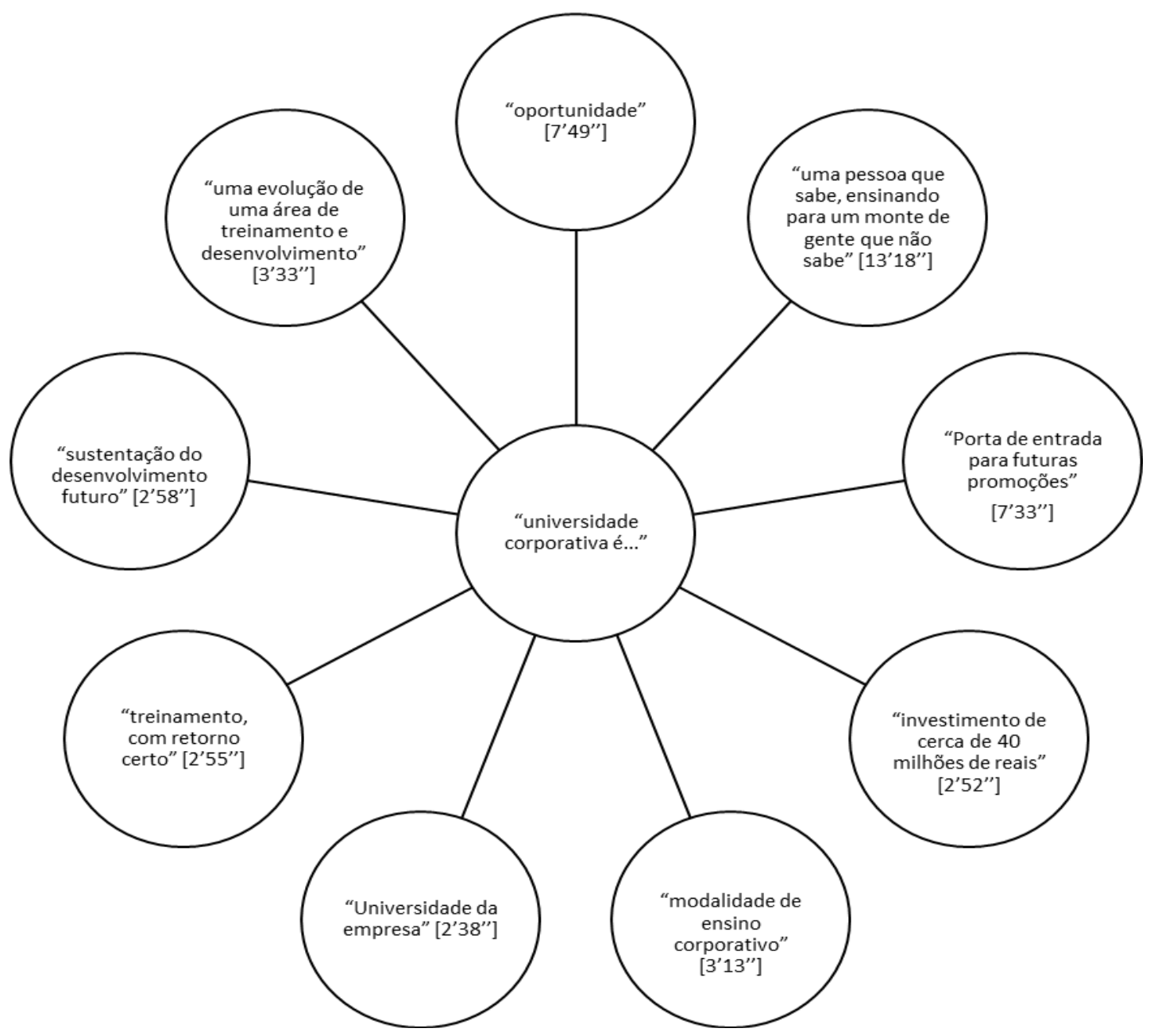

Figura 2 - ocorrências que retomam "universidade corporativa é" direta ou indiretamente no vídeo jornalístico, nas minutagens indicadas por (')minutos e (")segundos. 
Como podemos perceber nas ocorrências que trazemos na figura 2, o programa jornalístico, ao tentar definir o que é uma universidade corporativa, delimita o que pertence e o que não pertence à rede de sentidos dessa instituição. Nesses dizeres, a universidade é significada como meio de qualificação para o mercado de trabalho, como se marca em "porta de entrada para futuras promoções" [7'33'"], é uma "oportunidade" [7'49'] para o sujeito funcionário que imaginariamente busca alcançar o sucesso profissional, esse que só depende do próprio sujeito, uma vez que a empresa "investe" [2'52'] em qualificação. Diante disso, o vídeo jornalístico significa os sujeitos funcionários, como se todos tivessem reais condições de crescimento dentro da empresa, quando não há reais condições de crescimento para todos os funcionários e tampouco, emprego para todos, tendo em vista que o sistema econômico em que vivemos reproduz mais-valia sobre a mão de obra barata (qualificada). Como não se diz da desigualdade do sistema econômico, e tampouco de porque as universidades tradicionais não atenderiam as tais demandas do mercado, as universidades corporativas se projetam sobre os sujeitos via o discurso da meritocracia, que é naturalizado no dizer da mídia, produzindo efeitos de sentidos de uma simples seleção.

O funcionamento do não-dito também contribui para os efeitos de sentido sobre a universidade corporativa, uma vez que não se fala do sucateamento das universidades públicas, nem coloca em debate a existência das universidades privadas. Os sujeitos alunos da universidade corporativa são significados como aqueles que aprendem conteúdos específicos de funcionamento da empresa e, mesmo assim, o discurso sobre as universidades corporativas no vídeo sustenta que o funcionário (em plena consonância com a empresa) é quem ganharia com essa formação complementar, visto que supre uma deficiência de formação deixada pela "universidade tradicional".

\section{CONCLUINDO}

Percebemos que o discurso sobre a universidade corporativa funciona em consonância com a automatização, pela via do algoritmo, das relações de trabalho, que em uma sociedade de classes, reconfigura a antiga divisão entre trabalho braçal e trabalho intelectual. O surgimento de uma universidade corporativa - customizada para atender a demanda, não de indivíduos de carne e osso, mas de um sujeito espectral, uma ficção jurídica - parece trazer algo do mesmo, um estranho familiar, em condições de produção (aqui enfatizando as relações de produção propriamente ditas) diferentes. Esse estranho familiar, no entanto, toca em um problema para o discurso liberal clássico: o de se reconhecer os interesses dos indivíduos concretos, o da recusa ao monopólio e das mazelas do corporativo. O acontecimento da corporação moderna talvez marque um ponto de inflexão que ainda não conquistou plenamente seu alcance. É possível vislumbrar algo desse processo de desencarnação espectral (essa pessoa) entranhado nas relações de produção na presença cada vez mais insidiosa do algoritmo a coordenar, hierarquizar, administrar a vida laboral do trabalhador e seus modos de cooperação em larga escala. Esse é um aspecto que temos de prestar atenção, pois como nos lembra Pêcheux:

O aspecto ideológico da luta para a transformação das relações de produção se localiza, pois, antes de mais nada, na luta para impor, no interior do complexo dos aparelhos ideológicos de Estado, novas relações de desigualdade-subordinação. (PÊCHEUX, 2009, p. 133) 
Por fim, só resta dizer que seria talvez muito cômodo a dois acadêmicos lançarem uma crítica à universidade corporativa sem também pensar o lugar contraditório da própria universidade acadêmica no seio do mundo capitalista. Lembremos então de um texto corajoso de Maurício Tragtenberg, A Delinquência Acadêmica, em que ele mostra o funcionamento classista da universidade em plena ditadura militar. Em que "a crítica à ideologia é feita nos chamados cursos críticos, que desempenham a função de tranquilizante no meio universitário" (TRAGTENBERG, 1979). Resultando um sujeito crítico conformado, quando este aceita a divisão do trabalho da crítica, se aparta da luta dos movimentos políticos de seu tempo e cede ao sobretrabalho do produtivismo regulado pelo algoritmo da plataforma lattes entre outros, ainda mais ansiosamente quando suas condições de trabalho são precarizadas (via corte de recursos, sucateamento etc.). Se a universidade é também "palco de uma dura e ininterrupta luta de classes", essa luta não se dá isolada, apartada de outros palcos.

\section{REFERÊNCIAS}

DELA-SILVA, Silmara; TEIXEIRA, Karoline da Cunha. Do mercado à universidade? O discurso sobre as universidades corporativas e os sujeitos na mídia. Rio de Janeiro: Relatório de Iniciação Científica, FAPERJ, 2017.

HARARI, Yuval Noah. Sapiens: uma breve história da humanidade. Trad. Bras. Porto Alegre: L\&PM, 2016.

MARTINS, Mônica de Sousa. Entre a Cruz e o Capital: as corporações de ofício no Rio de Janeiro após a chegada da família real (1808-1824). Rio de Janeiro: Garamond, 2008.

MARIANI, B. O PCB e a imprensa: os comunistas no imaginário dos jornais (1922-1989). Campinas: Editora da Unicamp, 1998.

MARIANI, B.; MAGALHÃES, B. "Eu quero ser feliz". O sujeito, seus desejos e a ideologia. Em: INDURSKY, F.; MITTMANN, S.; LEANDRO-FERREIRA, M.C. (Orgs.). Memória e história na/da análise do discurso. Campinas: Mercado de Letras, 2011. p. 125-141.

MENEZES, Simone Guimarães. Universidade corporativa: uma educação estratégica. ABT Associação Brasileira de Tecnologia Educacional. Disponível em http://www.abtbr.org.br/index.php?option $=$ com content $\&$ view $=$ article \&id $=309$ :universidade-corporativa-umaeduca-estratca\&catid=15:educa\&Itemid=80. Acesso em 20 out. 2015.

NASCIMENTO JUNIOR, Gilberto da Silva. A valorização do capital intelectual através da educação corporativa. Monografia. MBIS [Master Business Information Systems], Pontifícia Universidade Católica de São Paulo, São Paulo, 2006. Disponível em http://www.mbis.pucsp.br/monografias/Monografia_- Gilberto da_Silva.pdf. Acesso em 20 out. 2015.

OLIVEIRA, Teresinha. A Universidade Medieval: uma memória. Mirabilia [Revista Eletrônica de História Antiga e Medieval], 6, jun-dez 2006. Disponível em https://dialnet.unirioja.es/servlet/articulo?codigo=2227065. Acesso em 27 ago 2017.

OTRANTO, Celia Regina. Universidades corporativas: o que são e para que servem? $30^{\mathrm{a}}$ Reunião Anual da ANPED, Caxambu, 2007. Disponível em http://www.anped11.uerj.br/30/GT11-2852-Int.pdf. Acesso em 20 out. 2015.

PÊCHEUX, M. (1969). Análise automática do discurso (AAD-69). Em: GADET, F.; HAK, T. (Orgs.). Por uma análise automática do discurso. $4^{\mathrm{a}}$. ed. Trad. Bras. Campinas: Ed. da Unicamp, Editora da Unicamp, 2010.

PÊCHEUX, M. Semântica e discurso: uma crítica à afirmação do óbvio. $3^{\text {a }}$. ed. Trad. Bras. Campinas: Editora da Unicamp, 2009. 
PROGRAMA CONTA CORRENTE, Globo News. O que é universidade corporativa? 18/11/2013 (19min10s). Disponível em https://www.youtube.com/watch?v=Ge7q4-JsuR4. Acesso em 20 nov. 2015.

SMITH, Adam. Inquérito sobre a natureza e as causas da riqueza das nações. Lisboa: Fundação Calouste Gulbenkian, 1980, vols. I e II.

TRAGTENBERG, Maurício. A Delinquência Acadêmica. Verve, 2, 175-184, São Paulo, NUSOL, PUC-SP, 2002.

Artigo recebido em: out. de 2019.

Aprovado e revisado em: nov. de 2019.

Publicado em: dezembro de 2019.

Para citar este texto:

BECK, Maurício; TEIXEIRA, Karoline da Cunha. Do mesmo e do diferente: das corporações de ofício às universidades corporativas. Entremeios [Revista de Estudos do Discurso, ISSN 21793514, on-line, www.entremeios.inf.br], Seção Estudos, Programa de Pós-Graduação em Ciências da Linguagem (PPGCL), Universidade do Vale do Sapucaí (UNIVÁS), Pouso Alegre (MG), vol. 20, Especial, Dossiê "Língua, discurso e trabalho na contemporaneidade", p. 101-110, dez. 2019. DOI: http://dx.doi.org/10.20337/ISSN2179-3514revistaENTREMEIOSvol20pagina101a110 